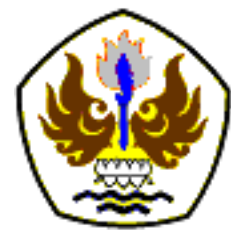

INFOMATEK

Volume 20 Nomor 1 Juni 2018

\title{
PENGARUH PERBEDAAN KOMPOSISI MANGAN PADA KOMPONEN JAW PLATE TERHADAP KEKERASAN DAN STRUKTUR MIKRO
}

\author{
Aa Santosa, Muhamad Jimi ${ }^{*}$ \\ Program Teknik Mesin \\ Fakultas Teknik - Universitas Singaperbangsa Karawang
}

\begin{abstract}
Abstrak: Telah dilakukan penelitian tentang pengaruh perbedaan komposisi Mangan pada komponen Jaw Plate terhadap Kekerasan dan struktur mikro. Pengujian ini dilakukan untuk mengetahui sifat mekanik dari baja Mangan Austenitik meliputi pengujian kekerasan skala Rockwell $C$ yang bertujuan untuk mengetahui kekerasan dan pengujian impak untuk mengetahui ketangguhan material tersebut. Metoda pengujian impak yang dilakukan adalah metode charpy. Dari hasil penelitian diperoleh kondisi as cast, penambahan Mn akan menaikan harga kekerasan dan menaikan harga impak. Begitu pula pada kondisi setelah dilakukan proses heat treatment. Dilakukan proses metalograpy untuk melihat perubahan fasa pada struktur mikro as cast dan setelah dilakukan proses heat treatment, struktur mikro yang terjadi pada baja Mangan Austenitik adalah karbida komplek, $\alpha+(\mathrm{FeMn})_{3} \mathrm{C}$.
\end{abstract}

Kata kunci: baja Mangan Austenitik, ketangguhan, kekerasan

\section{PENDAHULUAN}

Jaw crusher diperkenalkan oleh Blake dan Dodge, dan beroperasi dengan menerapkan penghancur bertekanan. Jaw crusher merupakan salah satu peralatan pemecah batu yang paling terkenal di dunia. Jaw crusher sangat ideal dan sesuai untuk melakukan proses penghancuran batu pada tahap pertama dan tahap kedua.

Dalam pengolahan mineral pertambangan, jaw crusher dapat digunakan untuk pengolahan

*aa_santosa72@yahoo.com

Pertama diterima : 18 Februari 2018

Direvisi : 30 April 2018

Disetujui untuk publikasi: 2 Mei 2018 menghancurkan bauksit, bijih tembaga, bijih emas, bijih besi, bijih timah, mangan, bijih perak, bijih seng, alunite, aragonit, arsenik, aspal, ball clay, barit, basal, bentonit, kokas, beton, dolomit, feldspar, granit, kerikil, gipsum, kaolin, batu kapur, marmer, kuarsa, pasir silika, dan lain-lain (ASM Handbook, 2005 [1]).

Untuk mendukung pengoperasiannya, jaw crusher membutuhkan komponen yang berkelanjutan supaya mesin bisa terus beroperasi, dimana komponen tersebut adalah Jaw plate bagian yang berinteraksi langsung dengan objek yang akan diolah (dihancurkan). Jaw Plate adalah salah satu bagian komponen 
dari mesin Jaw crusher yang berfungsi untuk menghancurkan batu-batu yang terdapat di daerah pertambangan. Penggunaan komponen tersebut disyaratkan harus dapat menekan beban yang berat. Karena penggunaan yang berat, maka komponen ini merupakan komponen yang penting pada saat mesin jaw crusher dioperasikan (dijalankan). Dibutuhkan sifat mekanik seperti tahan aus, sehingga pada waktu proses pemakaiannya memiliki sifat kekuatan yang tinggi, karena beban pemakaian yang cukup berat (ASTM, 2004 [2]). Secara teknologi material, komponen ini menggunakan baja tahan aus dimana penguasaan teknologi di dalam negeri masih kurang. Secara teknologi proses, karena bentuk komponen ini yang rumit dan terbuat dari baja paduan maka dibutuhkan teknologi proses yang tepat seperti desain pengecoran, pemilihan cetakan, pemaduan dan proses peleburan serta proses perlakuan panas (heat treatment) untuk dapat menghasilkan produk dengan standar yang disyaratkan.

Pembuatan jaw plate dilakukan dengan menggunakan teknik pengecoran (gravity casting) dimana teknik pengecoran ini menggunakan cetakan pasir sebagai wadah pembuatan jaw plate, proses dimulai dengan cara pembuatan pola awal jaw plate dengan menggunakan kayu, selanjutnya dari pola tersebut dibuat cetakan jaw plate dari pasir (Amanto, 1999 [3]).
Diharapkan hasil penelitian ini dapat memperoleh teknologi material maupun teknologi proses untuk menghasilkan Jaw plate dengan kualitas yang baik, sekaligus mendapatkan teknologi proses yang dapat diterapkan di dalam negeri serta memiliki nilai ekonomis yang baik. Pada akhirnya akan berdampak terhadap kemandirian serta dapat meningkatkan pertumbuhan industri nasional.

\section{METODOLOGI PENELITIAN}

Penelitian mengenai pengaruh perbedaan komposisi Mangan pada komponen Jaw Plate terhadap kekerasan dan strurktur mikro dilakukan berdasarkan praktek yang dilaksanakan di MIDC Jln. Sangkuriang No.12 Bandung, bagian pengecoran. Dari hasil penelitian diharapkan dapat diketahui pengaruh prosentase Mangan terhadap kekerasan dan struktur mikro. Alur penelitian selengkapnya mengikuti diagram alir di pada Gambar 1.

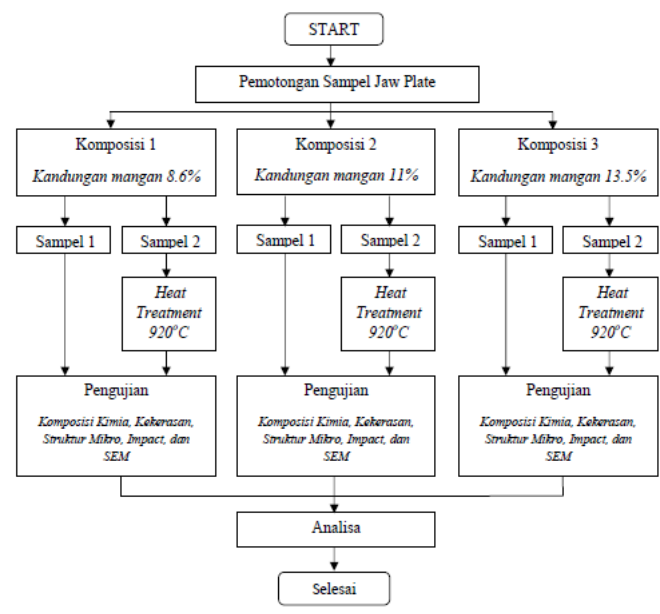

Gambar 1

Diagram alir Proses Penelitian dan Pengujian Jaw Plate 


\section{Pemotongan sampel uji}

Pemotongan sampel uji dilakukan dengan menggunakan gergaji mesin, dari setiap masing-masing komposisi dipotong menjadi dua bagian, dan dari dua bagian tersebut di potong kembali untuk mendapatkan ukuran sampel yang lebih kecil, dari ketiga komposisi yang dipotong maka didapatkan 6 sampel untuk pengujian.

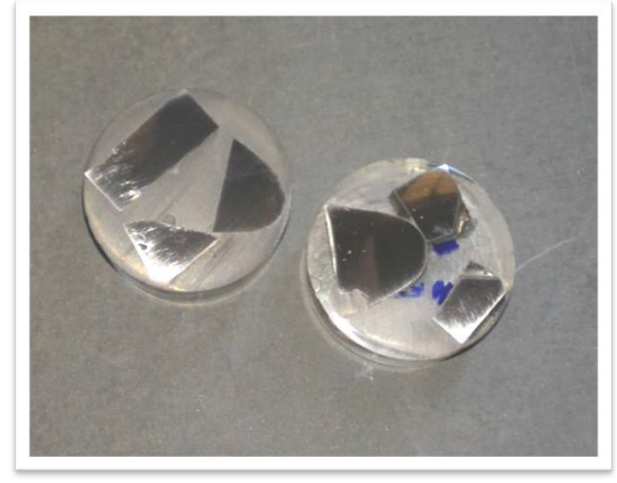

\section{Gambar 2}

Pemotongan sampel yang sudah dimounting

\section{Perlakuan Panas}

Setelah proses pemotongan untuk keperluan pengujian, sampel selanjutnya masuk ke proses Perlakuan Panas, dari 6 sampel yang tersedia hanya 3 sampel yang mendapat proses perlakuan panas, 3 sampel tersebut mewakili dari setiap komposisi yang ada. Ketiga sampel uji diberi perlakuan panas dengan metode Austenisasi sampai pada suhu $920^{\circ} \mathrm{C}$ dan holding time atau ditahan selama 1 jam pada suhu dalam tungku, setelah ditahan selama 1 jam kemudian dilakukan pendinginan atau quenching dengan metode pendinginan cepat (direct quenching) dengan menggunakan media pendingin air.

\section{Pengujian kekerasan}

Uji kekerasan dilakukan pada sampel awal, sampel yang telah mendapat perlakuan panas dan kedua sampel yang tidak mendapat perlakuan panas. Dalam pengujian kekerasan pada penelitian ini metode uji kekerasan yang dilakukan adalah uji kekerasan Rockwell. Untuk pengujian dengan metode Rockwell dipakai standar Rockwell C, yaitu menggunakan indentor kerucut intan dan beban $150 \mathrm{~kg}$. Setiap spesimen diuji keras sebanyak 5 kali dan diambil rata-ratanya, lama waktu indentsi adalah 2 detik untuk selanjutnya dilakuka pengujian struktur mikro, pengujian kompisisi, pengujian impak sesuai standar yang berlaku di MIDC.

\section{ANALISIS DAN PEMBAHASAN}

Telah dilaksanakan pengujian terhadap jaw plate yang ditunjukan pada tabel dan gambar berikut.

Tabel 1

Komposisi Kimia Jaw Plate Ascast 1

\begin{tabular}{|l|l|l|l|l|l|l|l|}
\hline \multirow{2}{*}{$\begin{array}{l}\text { Jaw } \\
\text { plate } \\
\text { Ascast 1 }\end{array}$} & \multicolumn{7}{|c|}{ Komposisi Kimia } \\
\cline { 2 - 8 } & $\mathrm{C}$ & $\mathrm{Si}$ & $\mathrm{Mn}$ & $\mathrm{P}$ & $\mathrm{S}$ & $\mathrm{Cr}$ & $\mathrm{Cu}$ \\
\cline { 2 - 8 } & 1,7 & 1,1 & 8,6 & 0,04 & $<0,002$ & 3,5 & 0,1 \\
\hline
\end{tabular}

Tabel 2

Komposisi Kimia Jaw Plate Ascast 2

\begin{tabular}{|l|l|l|l|l|l|l|l|}
\hline \multirow{2}{*}{$\begin{array}{l}\text { Jaw } \\
\text { plate }\end{array}$} & \multicolumn{7}{|c|}{ Komposisi Kimia } \\
\cline { 2 - 8 } Ascast 2 & $\mathrm{C}$ & $\mathrm{Si}$ & $\mathrm{Mn}$ & $\mathrm{P}$ & $\mathrm{S}$ & $\mathrm{Cr}$ & $\mathrm{Cu}$ \\
\cline { 2 - 8 } & 1,7 & 0,7 & 11 & 0,04 & $<0,002$ & 1,7 & 0,1 \\
\hline
\end{tabular}


Tabel 3

Komposisi Kimia Jaw Plate Ascast 1

\begin{tabular}{|l|l|l|l|l|l|l|l|}
\hline Jaw & \multicolumn{7}{|c|}{ Komposisi Kimia } \\
\cline { 2 - 8 } $\begin{array}{l}\text { plate } \\
\text { Ascast 3 } 3\end{array}$ & $\mathrm{C}$ & $\mathrm{Si}$ & $\mathrm{Mn}$ & $\mathrm{P}$ & $\mathrm{S}$ & $\mathrm{Cr}$ & $\mathrm{Cu}$ \\
\cline { 2 - 8 } & 1,0 & 0,6 & 13 & 0,04 & $<0,002$ & 0,3 & $<0,001$ \\
\hline
\end{tabular}

Setelah dilakukan pengujian komposisi maka dilakukan pengujian kekerasan terhadap Jaw Plate.

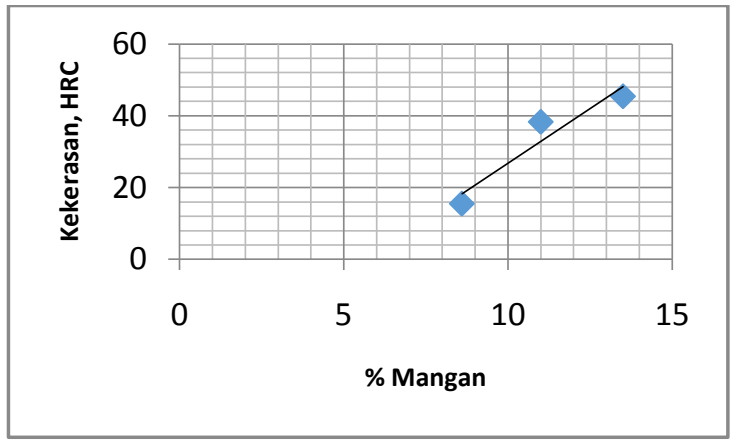

Gambar 3

Data pengujian Rockwell jaw plate ascast

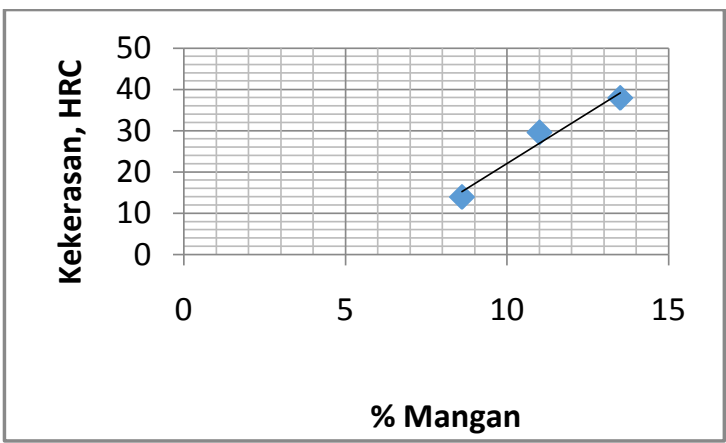

Gambar 4

Data pengujian Rockwell Jaw plate Heat Treatment

Terlihat proses laku panas pada proses hardening dengan mendinginkan cepat selain berpengaruh terhadap komposisi dan struktur mikro juga berpengaruh terhadap nilai kekerasan. Semakin cepat laju pendinginan semakin banyak pula terbentuk martensit.

Spesimen yang tanpa mendapatkan perlakuan hardening memiliki kekerasan rendah. Struktur kristal ferrit yang dominan menjadikan rendahnya nilai kekerasan pada spesimen. Namun jumlah terbentuknya $\mathrm{Fe}_{4} \mathrm{Mn}_{5}$ yang berstruktur FCC serta karbida mangan $(\mathrm{FeMn})_{3} \mathrm{C}$ menumbangkan nilai kekerasan pada baja mangan yang tanpa diberi perlakuan hardening. Sehingga nilai yang dicapai hampir sama atau masih kurang signifikan jika dibandingkan dengan yang mendapatkan perlakuan panas berupa hardening. Pada spesimen yang diberikan perlakuan panas berupa hardening dengan didinginkan cepat memiliki nilai yang lebih tinggi jika dibandingkan spesimen baja mangan tanpa mendapatkan perlakuan. Unsur martensit berperan penting dalam meningkatkan nilai kekerasan. Adanya tegangan akibat dari karbon yang terperangkap ke dalam struktur kristal BCT. Martensit merupakan larutan padat lewat jenuh ini adalah struktur yang metastabil.

Selama pendinginan, terjadi perpindahan panas spesimen dengan media pendingin. Kontak antara media pendingin dengan spesimen mengakibatkan perubahan temperatur yang relatif cepat dan berbedabeda. Semakin cepat laju pendinginan yang 
terjadi maka akan semakin tinggi nilai kekerasan yang diproleh oleh baja.

Proses selanjutnya dilakukan pengujian impak terhadap jaw plate yang ditunjukan pada grafik berikut.

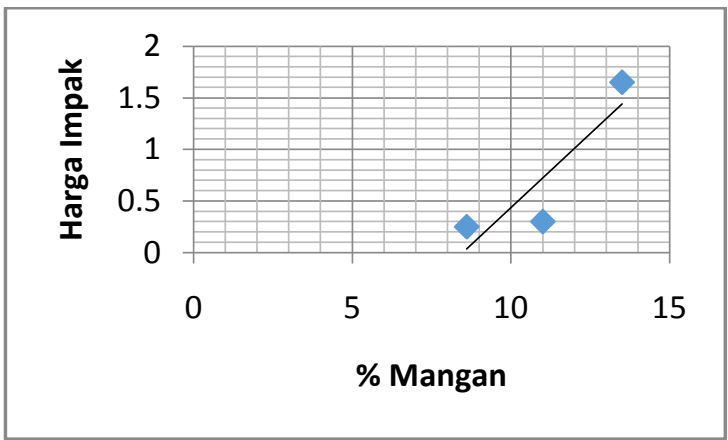

Gambar 5

Grafik Harga Impak Terhadap \% Mangan, as cast

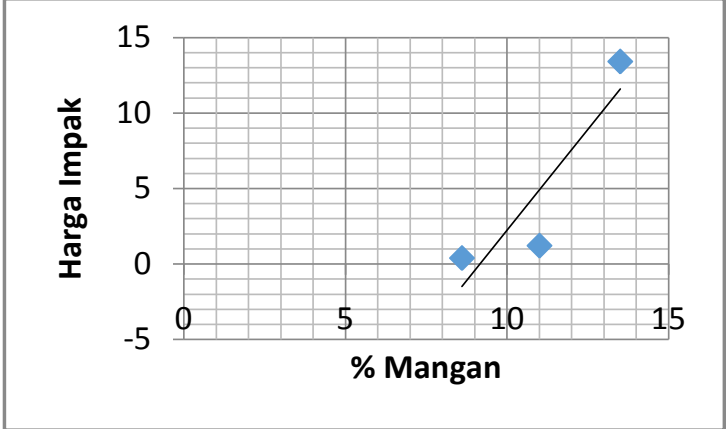

Gambar 6

Grafik Harga Impak Terhadap \% Mangan, Heat

Treatment

Harga impak lebih tinggi dibandingkan jaw plate yang tidak mengalami heat treatment.

Baja mangan termasuk dalam katagori baja mangan austenitic, baja dengan kandungan Mn (mangan) yang tinggi dengan kandungan
Carbon antara 0,8-1,25\% C serta nilai kekerasan as cast 15,6 sampai 45,44 HRC.

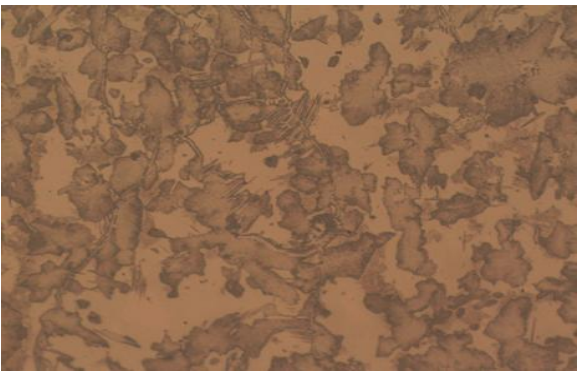

Gambar 7

Struktur Mikro Jaw Plat ascast Mn 8.6\%, pembesaran $200 x$

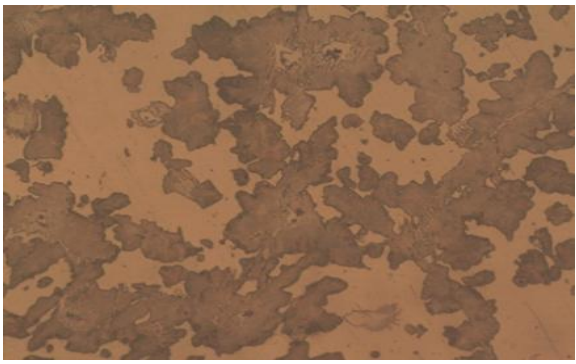

Gambar 8

Struktur Mikro Jaw Plate ascast Mn $11 \%$, pembesaran $200 x$

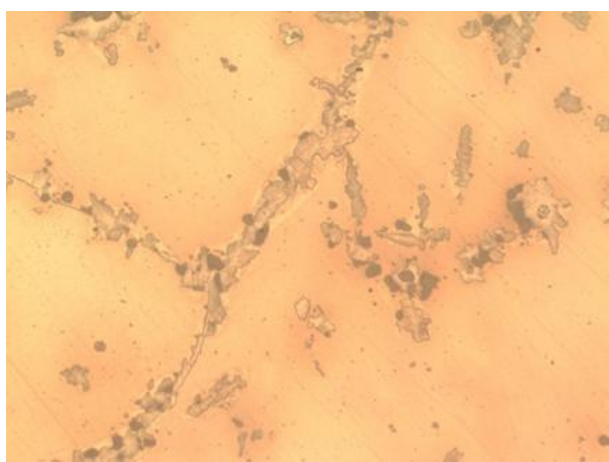

Gambar 9

Struktur Mikro Jaw Plate ascast Mn $13.5 \%$, pembesaran 200x

Dengan struktur fasa austenite yang stabil hingga temperatur kamar. Baja mangan 
memiliki kekerasan, kekuatan dan ketangguhan, keuletan dan ketahanan terhadap aus yang tinggi. Baja mangan berbeda dari baja lain yang mendapatkan pengerasan permukaan dengan kedalaman kekerasan tetap seperti nitriding dan carburizing. Kekerasan yang dimiliki baja mangan terdapat keuletan yang tinggi didalamnya. Sehingga dapat dikatakan baja mangan memiliki ketangguhan yang tinggi. Perlakuan panas diberikan untuk mendapatkan nilai kekerasan tertentu pada baja mangan. Perlakuan panas dengan didinginkan cepat menggunakan media pendingin air memberikan nilai kekerasan yang tinggi. Dengan demikian memperpanjang usia pemakaian pada baja mangan tersebut. Salah satu metode perlakuan panas yang dilakukan dalam penelitian ini untuk meningkatkan nilai kekerasan suatu baja yaitu dengan melakukan quenching, yaitu perlakuan panas dengan cara memanaskan baja pada temperatur austenisasinya kemudian didinginkan dengan cepat.

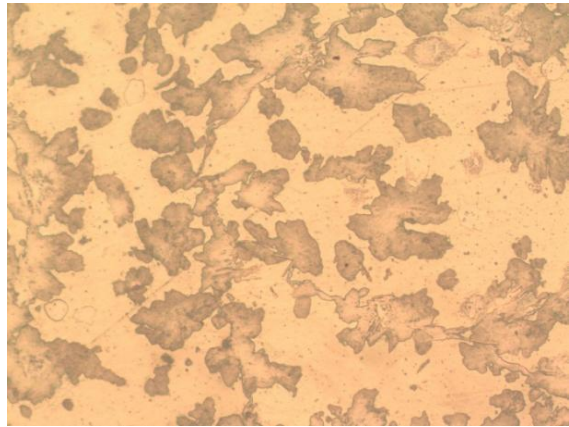

Gambar 10

Struktur Mikro Jaw Plate Heat Treatment Mn 8.6\%, pembesaran 200x

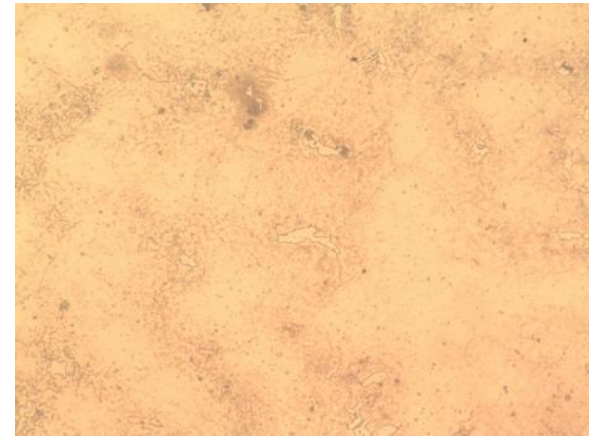

Gambar 10

Struktur Mikro Jaw Plate Heat Treatment Mn $11 \%$, pembesaran 200x

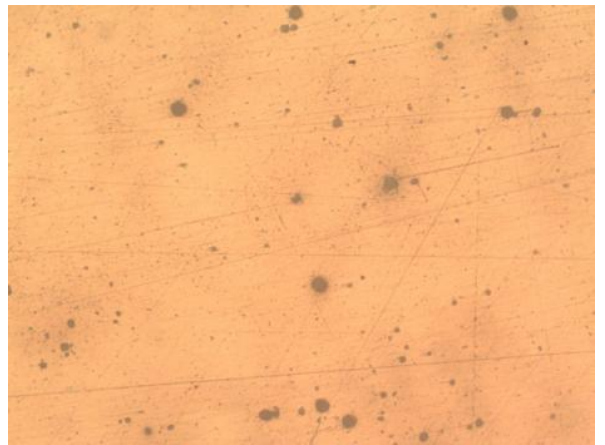

Gambar 11

Struktur Mikro Jaw Plate Heat Treatment Mn $13.5 \%$, pembesaran 200x

Perbedaan jumlah martensit yang terbentuk berbeda seiring kecepatan laju pendinginnya. Semakin cepat laju pendinginan maka semakin cepat pula martensit yang terbentuk pada pendinginan setelah pemanasan $950^{\circ} \mathrm{C}$. Perbandingan nampak kontras pada pendinginan air dengan pendinginan oli. Pada pendinginan air martensit yang terbentuk $90 \%$ sedangkan pada pendinginan oli martensit 
hanya terbentuk 40\% lebih sedikit jika dibandingkan dengan pendinginan air.

Waktu pendinginan yang lebih lambat, pada pendinginan oli mengakibatkan austenit tidak seluruhnya bertransformasi menjadi martensit (Gambar 12). austensit sisa memiliki waktu untuk untuk bertransformasi menjadi ferrit dan austensit. Austensit yang terbentuk stagnan tetap menjadi gamma (FCC) terbentuk karena setelah dipanaskan hingga temperatur $950^{\circ} \mathrm{C}$ kemudian didinginkan hingga temperatur kamar unsur mangan yang tinggi pada baja hadfield berikatan dengan Besi $\mathrm{Fe}$ dan $\mathrm{O}$ sehingga terbentuk $\mathrm{Fe}_{4} \mathrm{MnO}_{5}$ dengan struktur kristal FCC (gamma) austensit.

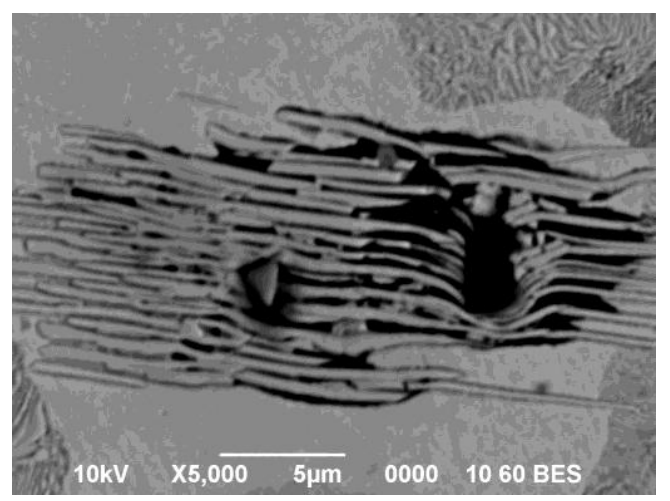

Gambar 12

Hasil foto Jaw Plate ascast Mn 8,6 \%

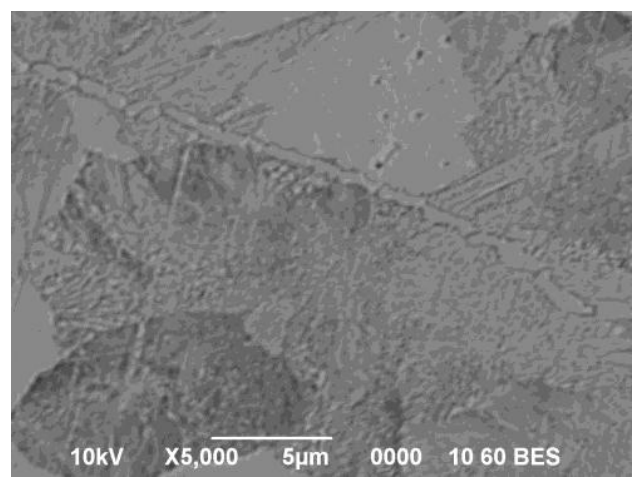

Gambar 13

Hasil foto SEM jaw plate ascast Mn $11 \%$

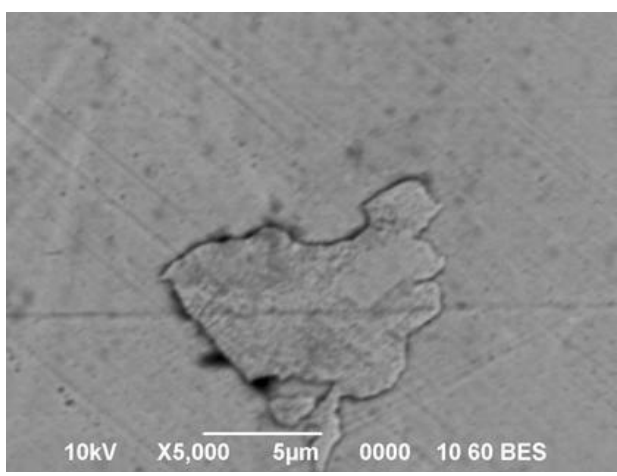

Gambar 14

Hasil foto SEM jaw plate ascast Mn $13.5 \%$

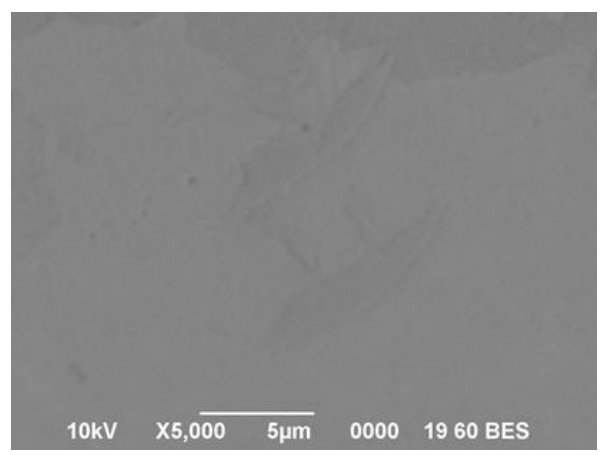

Gambar 15

Hasil foto SEM jaw plate Heat Treatment Mn $8.6 \%$ 


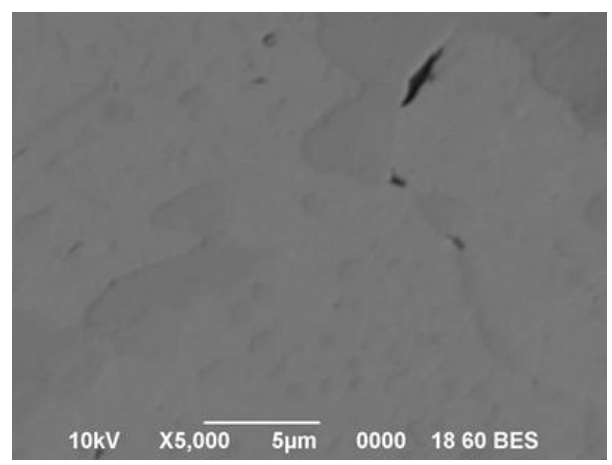

Gambar 16

Hasil foto SEM jaw plate Heat Treatment Mn $11 \%$

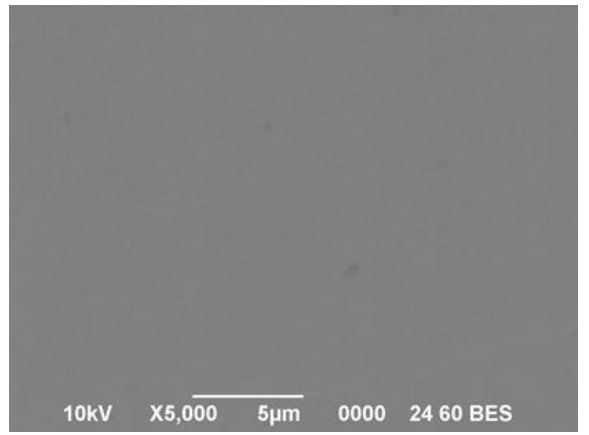

Gambar 17

Hasil foto SEM jaw plate Heat Treatment Mn $13.5 \%$

\section{KESIMPULAN}

Dari hasil penelitian yang dilakukan baik pada material as cast maupun maaterial yang sudah mengalami proses heat treatmen, dapat disimpulkan sebagai berikut:

1. Material yang digunakan untuk membuat Jaw plate adalah Baja mangan austenitik

2. Sifat mekanik yang diperlukan untuk jaw plate adalah selain kekerasan juga harus memiliki sifat mekanik ketangguhan yang baik karena proses kerja dari Jaw plate selain mengalami gesekan dengan benda keras juga mengalami benturan-benturan secara tiba-tiba.

3. Dilihat dari hasil pengujian terhadap material jaw plate terjadi perubahan harga impak dengan bertambahnya prosentase Mangan.

4. Struktur mikro yang terjadi pada Baja Mangan adalah Karbida Komplek, $\alpha+\mathrm{Fe}(\mathrm{Mn})_{3} \mathrm{C}$

5. Penambahan unsur Mangan dalam Baja dapat menaikan kuat tarik, sehingga Baja mempunyai sifat kuat dan tangguh.

\section{DAFTAR PUSTAKA}

[1] ASM Handbook. 2005. Volume 1, Propertties and Selection: Iron Steels and High Performance Alloys. ASM International

[2] ASTM E 10-01. 2004. Standart Test Method for Brinell Hardness of Metallic Materials ASTM International

[3] Amanto, Hari. 1999. Ilmu Bahan. Bumi Aksara, Jakarta

[4] Amstead, BH.1997. Teknologi Mekanik jilid 1. Erlangga, Jakarta 